\title{
Growth of high quality, high density single-walled carbon nanotube forests on copper foils
}

\author{
Guofang Zhong $^{1 *}$, Junwei Yang ${ }^{1}$, Hisashi Sugime ${ }^{1}$, Rahul Rao ${ }^{2, \dagger}$, Jianwei Zhao ${ }^{3}$, Dameng Liu ${ }^{4}$, Avetik \\ Harutyunyan $^{2}$, John Robertson ${ }^{1}$ \\ ${ }^{1}$ Department of Engineering, University of Cambridge, CB2 1PZ, United Kingdom \\ ${ }^{2}$ Honda Research Institute USA Inc., Columbus, Ohio 43212, USA \\ ${ }^{3}$ School of Mechanical Electronic \& Information Engineering, China University of Mining \& Technology, \\ Beijing 10083, China \\ ${ }^{4}$ State Key Laboratory of Tribology, Tsinghua University, Beijing 100084, China
}

\begin{abstract}
We demonstrate the growth of high quality single-walled carbon nanotube (SWCNT) forests on commercial Cu foils by cold-wall chemical vapor deposition. Time-of-flight secondary ion mass spectrometry was employed to study the effect of annealing on the catalyst evolution with or without an $\mathrm{AlO}_{\mathrm{x}}$ barrier layer. X-ray photoelectron spectroscopy was used to investigate the chemical states of the catalyst and the barrier layer. SWCNT forests can be reproducibly grown on $\mathrm{Cu}$ foils sputter-coated with $\mathrm{Al}$ and $\mathrm{Fe}$ layers as thin as $6 \mathrm{~nm}$ and $0.4 \mathrm{~nm}$, respectively. $\mathrm{Al}$ transforms into $\mathrm{AlO}_{\mathrm{x}}$ on exposure to air and during annealing. Most importantly, such a thin $\mathrm{AlO}_{\mathrm{x}}$ barrier layer ensures not only the growth of SWCNTs but also an Ohmic contact between the as grown SWCNTs and the $\mathrm{Cu}$ base as measured by a two-point probe station. The as-grown SWCNTs exhibit a bimodal distribution of diameters ranging from 0.6 to $4.5 \mathrm{~nm}$, with two peaks centered at $0.8 \mathrm{nn}$ and $2.6 \mathrm{~nm}$, respectively.
\end{abstract}

\section{Introduction}

Owning to their excellent physical properties such as high specific surface area and chemical inertness, carbon nanotubes (CNTs) are regarded as a promising material for many applications such as super-capacitors [1-3], composites [4], transparent conducting films [5-7], hydrophobic surfaces [8], gecko-like adhesive surfaces [911], nano electro-mechanical systems (NEMS) [12, 13], field emission devices [14, 15], interconnects for integrated circuits [16-20], ultrasensitive sensors [21] and thermal management materials [22-24], In recent years there has been a strong desire to grow CNT forests on metal substrates, especially on $\mathrm{Cu}$, which is the most widely used metal for the electrical and electronic industries due to its high electrical and thermal conductivity with relatively low cost. These applications require not only a high area density of CNTs but also a good contact between the CNTs and the substrates.

Processes have been developed to grow high area density $\left(10^{12}-10^{13} \mathrm{~cm}^{-2}\right)$ single-walled carbon nanotube (SWCNT) forests on insulating supports like $\mathrm{Al}_{2} \mathrm{O}_{3}$ by catalytic chemical vapor deposition (CVD) [25-28]. However, it is more difficult to grow CNT forests on metal substrates. Unlike oxide supports which are chemically stable, possess a low surface energy and can act as an efficient diffusion barrier of the catalyst [27, 29-31], a metal substrate usually has a higher surface energy and it can undergo complicated chemical reactions and physical changes under most CVD conditions [32-36]. These include oxidation, reduction, carbide formation, grain coarsening and alloying with the catalyst. These factors make it difficult to form high density catalytic nanoparticles on the metal surface by dewetting and they result in a rapid loss of catalyst by subsurface diffusion /alloying, which in turn leads to the growth of low density CNTs or no growth at all on the substrate.

In the past decade, steady progresses have been made in growing CNT forests on some conductive substrates such as Ti, Ta, TiN, TaN, TiSiN and $\mathrm{CoSi}_{2}$, etc.[18, 32, 34-43] However, it seems extremely difficult to grow CNT forests directly on $\mathrm{Cu}$ coated only with a thin catalyst film [44-48]. This is probably because most of the efficient catalysts such as $\mathrm{Fe}, \mathrm{Co}$ and $\mathrm{Ni}$ can easily form solid solutions with $\mathrm{Cu}$ [49]. The most common method to avoid this is to coat an $\mathrm{Al}_{2} \mathrm{O}_{3}$ barrier layer between the catalyst and the metal substrate [24, 50-52]. However, as commercial $\mathrm{Cu}$ foils usually have rough surfaces, it was reported that thicker than normal catalyst (up to $3.5 \mathrm{~nm}$ ) and $\mathrm{Al}_{2} \mathrm{O}_{3}$ barrier layers (up to $30 \mathrm{~nm}$ ) are needed to grow less dense multi-walled carbon

\footnotetext{
* Corresponding author.

Email address: gz222@cam.ac.uk, zhongchina@msn.com (G. Zhong).

${ }^{\dagger}$ Present address: Air Force Research Laboratory, Wright-Patterson Air Force Base, Ohio 45433, USA
} 
nanotube (MWCNT) forests [24]. This limits the electrical performance because $\mathrm{Al}_{2} \mathrm{O}_{3}$ thicker than $3 \mathrm{~nm}$ acts as an insulator [40].

Horibe et al. [37] did some pioneering work to grow CNT forests on $\mathrm{Cu}$ films by introducing a conductive Ta barrier layer between the catalyst and the substrate. Later, Yamazaki et al. [39] reported the growth of closely packed MWCNT forests on $0.5 \mathrm{~nm}$ Co (top) $/ 0.5 \mathrm{~nm}$ TiN/10 nm TaN/Cu layers by a multi-step growth method, including a new approach to immobilize the catalytic nanoparticles using plasma-based CVD. Very recently, growth of CNT forests on $\mathrm{Cu}$ using atomically thin graphene as a medium has been reported [53, 54]. Zhu et al. [53] achieved this by using an "Odako" tip growth mechanism [55], which involves the E-beam evaporation of 3-10 nm Al${ }_{2} \mathrm{O}_{3}$ (top) $/ 1 \mathrm{~nm} \mathrm{Fe}$ on CVD graphene/Cu and then the growth of CNTs. It is claimed that the $\mathrm{Al}_{2} \mathrm{O}_{3}$ layer and the $\mathrm{Fe}$ catalyst is lifted up by CNT forests, resulting in a seamless three-dimensional CNT-graphene hybrid material on $\mathrm{Cu}$. However, this requires a porous top $\mathrm{Al}_{2} \mathrm{O}_{3}$ layer; otherwise the CNT growth may not occur due to the lack of gas access. Rao et al. [54] made another approach to direct growth of CNT forests on graphene /Cu by using vapor-phase catalyst delivery CVD, The key factor is to use a defect-rich CVD graphene, in which the defects stabilize the adhesion of catalyst nanoparticles to the graphene layer. However, this may limit the density of CNTs. Earlier, the vapor-phase catalyst delivery CVD was also employed to grow CNT forests on $\mathrm{Cu}$ (coated with $20 \mathrm{~nm} \mathrm{Au}$ (top) /12 nm Cr) and Inconel alloys [56-58].

In this paper, we attempt to grow SWCNT forests on $\mathrm{Cu}$ foils sputter-coated with $\mathrm{Al}$ and $\mathrm{Fe}$, which borrows our previous idea for growing the ultra-high density SWCNTs on $\mathrm{SiO}_{2}$ substrates [28]. It is to use DC magnetron sputtering to coat $\mathrm{Al}$ and $\mathrm{Fe}$ layers as thin as possible on $\mathrm{Cu}$ foils. The $\mathrm{Al}$ then oxidises to form a $\mathrm{AlO}_{\mathrm{x}}$ barrier layer on exposure to air and during annealing of substrates, to form a denser diffusion barrier layer for the $\mathrm{Fe}$ catalyst. We demonstrate that high quality and high density SWCNT forests can be reproducibly grown on commercial $\mathrm{Cu}$ foils, sputter-coated with an Fe catalyst and an $\mathrm{Al}$ barrier layer as thin as $0.4 \mathrm{~nm}$ and $6 \mathrm{~nm}$, respectively. And it is achieved an Ohmic contact between the as-grown CNTs and the $\mathrm{Cu}$ base. Time-of-flight secondary ion mass spectrometry (TOF-SIMS) was employed to study the effect of annealing on the catalyst evolution with or without the $\mathrm{Al}$ barrier layer.

\section{Experimental}

$25 \mu \mathrm{m}$ thick $\mathrm{Cu}$ foils were chosen $(99.8 \% \mathrm{Cu}$, uncoated, Vendor: Alfa Aesar, part No: 046365.RH) as substrates. These were cleaned in ultrasonic baths of de-ionize water, acetone and isopropyl alcohol in the order of priority. This is to ensure our process can be applied directly to commercial $\mathrm{Cu}$ foils without doing chemical cleaning or surface polishing. Unless otherwise specified, we deposited a 5-20 nm Al layer, 0.4-1.0 nm Fe catalyst and 0.5 $\mathrm{nm} \mathrm{Al}$ top layer on $\mathrm{Cu}$ foils by DC magnetron sputtering in chronological order. Ar was used as the sputtering gas at a working pressure of $3.5 \times 10^{-3}$ mbar (base pressure $1 \times 10^{-6} \mathrm{mbar}$ ). The deposition rates for $\mathrm{Fe}$ and $\mathrm{Al}$ were $0.018 \mathrm{~nm} / \mathrm{s}$ and $0.022 \mathrm{~nm} / \mathrm{s}$ (averaged from thick films), respectively. After sputtering, the substrates were transferred or stored in air.

The growth of CNTs on Cu foils was carried out using cold-wall CVD [59]. Cu foils were suspended on $0.5 \mathrm{~mm}$ thick Si strip spacers over a flat PBN/PG heater as shown in the supplementary Fig. S1. An unsheathed type C thermocouple was used to monitor the temperature of the PBN/PG heater from its under surface. The targeting temperature is normally set to $760{ }^{\circ} \mathrm{C}$. When the heater is preheated from room temperature to $680{ }^{\circ} \mathrm{C}$ in 15 mbar $500 \mathrm{sccm} \mathrm{H}_{2}$, we then introduce 1-8\% $\mathrm{C}_{2} \mathrm{H}_{2}$ (volume concentration, with a total flow rate of $500 \mathrm{sccm}$ $\mathrm{C}_{2} \mathrm{H}_{2}+\mathrm{H}_{2}$ at 15 mbar) to start the CNT growth, which may last from tens seconds to a few minutes until we switch off the input gases, the heater power and vacuum the chamber to terminate the growth.

The as-grown CNT samples were characterized by Raman spectrometry (Renishaw inVia), scanning electron microscopy (SEM, Philips XL30 SFEG and Carl Zeiss Sigma) and transmission electron microscopy (TEM, FEI Tecnai F20). TEM specimens were prepared by scratching the TEM grids with the as-grown SWCNT samples. Simultaneous multiple element mapping and depth profile analysis of selected substrates before and after annealing were carried out by TOF-SIMS. $\mathrm{Cs}^{+}$was used as the ion source. X-ray photoelectron spectroscopy (XPS, PHI Quantera -II) was employed to investigate the chemical state of the catalyst and the barrier layer. The electrical measurements were performed on CNT samples with a two-point probe station (Keithley 4200-SCS) to obtain their current-voltage (I-V) curves. The tip diameter of the probe is about $20 \mu \mathrm{m}$.

\section{Results and discussions}

\subsection{Growth of high density SWCNT forests on $\mathrm{Cu}$ foils}


Fig. 1 shows some typical SEM images of SWCNT forests successfully grown on $0.5 \mathrm{~nm} \mathrm{Al}$ (top) $/ 0.4 \mathrm{~nm} \mathrm{Fe} / 6$ $\mathrm{nm} \mathrm{Al} / \mathrm{Cu}$ foil by cold-wall CVD. The sample was preheated in $\mathrm{H}_{2}$ for $1.5 \mathrm{~min}$ and grown with $2 \% \mathrm{C}_{2} \mathrm{H}_{2}$ for 0.5 min. Fig. 1a is a low magnification image, showing the overall surface morphology and uniformity of the asgrown forests; Fig. 1(b-d) show high magnification images corresponding to the top surface, the bottom surface (detached from the $\mathrm{Cu}$ foil by sharp tweezers) and the cross-section of the forests, respectively. The inset in Fig. $1 \mathrm{~d}$ shows the full cross section, from which a CNT forest height of $9.2 \mu \mathrm{m}$ was measured. Cracks resulted from strong Van der Waals attractions among SWCNTs were also seen all over the foil; however, they obviously were induced by the parallel rolling marks on $\mathrm{Cu}$. This feature is different from the random crack webs formed on smooth Si substrates [60]. By increasing the catalyst thickness from $0.4 \mathrm{~nm}$ to $1.0 \mathrm{~nm}$, the CNTs can change from SWCNTs to SWCNT + MWCNT mixtures and finally to MWCNTs. Cracks were rarely seen on less dense MWCNTs samples (Fig. S2). Note that dense SWCNTs can appear less aligned than equivalent MWCNTs forest because of the lower bending modulus of SCWNTs [61]. As our SWCNT forests grow via a root growth mechanism [62,63], the top surface records the initial nucleation and growth of CNTs with less density. Once the CNT nucleation is maximized, the highest density is achieved (Fig. 1(c, d)).
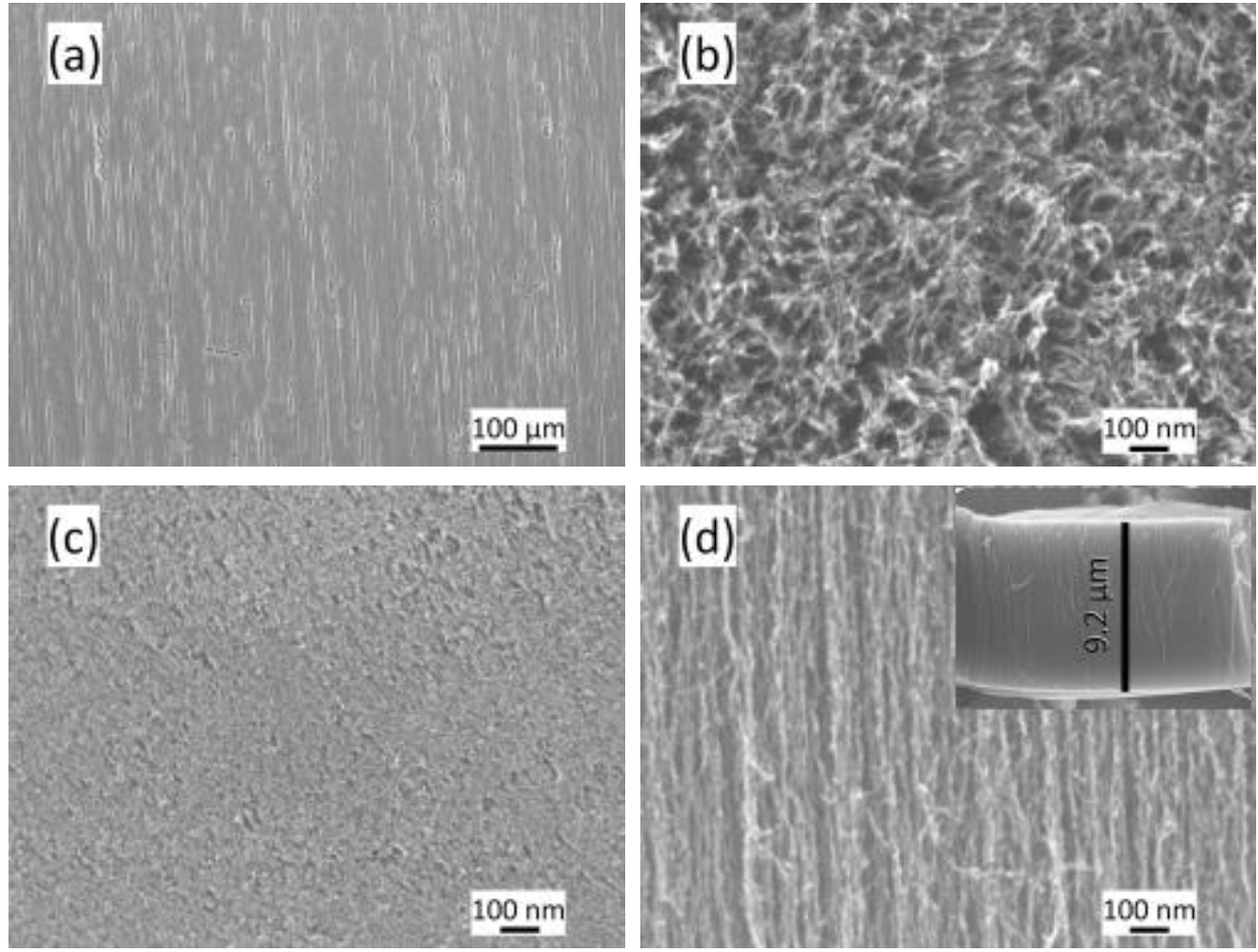

Fig. 1- SEM images of high density SWCNT forests grown on $0.5 \mathrm{~nm} \mathrm{Al}$ (top) $/ 0.4 \mathrm{~nm} \mathrm{Fe} / 6 \mathrm{~nm} \mathrm{Al} / \mathrm{Cu}$ foil by cold-wall CVD. (a) A low magnification image, the inset shows its full cross section $(\sim 9.2 \mu \mathrm{m})$; (b-d) High magnification images of (b) the top surface, (c) bottom surface detached from the $\mathrm{Cu}$ foil by sharp tweezers and (d) the cross-section of the as-grown SWCNT forests. CVD conditions: the sample was first pretreated in 500 $\mathrm{sccm} \mathrm{H}, 15 \mathrm{mbar}$ and $760^{\circ} \mathrm{C}$ for $1.5 \mathrm{~min}$, then grown in $10 \mathrm{sccm} \mathrm{C}_{2} \mathrm{H}_{2}+490 \mathrm{sccm} \mathrm{H}_{2}$ for $0.5 \mathrm{~min}$.

We can derive a mass density of the forests of $96 \mathrm{mg} \cdot \mathrm{cm}^{-3}$ from the mass gain of $9.2 \mu \mathrm{m}$-high SWCNT forests grown on a $\Phi 15 \mathrm{~mm} \mathrm{Cu}$ foil. This corresponds to an average areal density of $2.2 \times 10^{12} \mathrm{~cm}^{-2}$ for an average diameter of $1.9 \mathrm{~nm}$ by the weight gain method $[19,28]$. This is less dense than our ultra-high density SWCNTs using the same catalyst on $\mathrm{SiO}_{2}$ [28], but it is so far the highest area density of CNT forests on $\mathrm{Cu}$ [39]. More importantly, it is achieved by using a much simpler thermal CVD process.

Fig. 2 shows some characterization results of the as-grown SWCNTs by TEM and Raman spectrometry. It is clearly seen in Fig. 2a that the SWCNTs are straight and clean without any amorphous carbon attached to the sidewalls, suggesting a high growth quality. This agrees well with the high intensity ratio of the $\mathrm{G}$ band to the $\mathrm{D}$ band [64] $\left(I_{\mathrm{g}} / I_{\mathrm{d}}>10\right)$ of the Raman spectrum in Fig. 2c. The TEM images demonstrate that the CNTs grown on $\mathrm{Cu}$ have a very broad diameter distribution, spanning from 0.6 to $4.5 \mathrm{~nm}$ (Fig. 2b. The CNT diameter histogram in Fig. 2b shows that the distribution is bimodal, with two peaks centered at $0.8 \mathrm{~nm}$ and $2.6 \mathrm{~nm}$, respectively, 
giving a mean diameter around $1.9 \mathrm{~nm}$. This distribution is twice as broad as the unimodal distribution of the ultra-high density SWCNTs grown on $\mathrm{SiO}_{2} / \mathrm{Si}$ wafers using a similar catalyst but having the $\mathrm{Al}$ barrier layer oxidized on purpose [28]. The bimodal distribution is attributed to the evolution of catalyst microstructure by surface migration and Ostwald ripening [65-68]. Although the $\mathrm{Cu}$ substrate is different from $\mathrm{SiO}_{2}$, we think the property of the $\mathrm{AlO}_{\mathrm{x}}$ barrier layer may account more for the bimodal distribution. It can efficiently prevent the bulk diffusion of $\mathrm{Fe}$ into the $\mathrm{Cu}$, promote formation of catalytic nanoparticles, but the passive $\mathrm{AlO}_{\mathrm{x}}$ layer is not as effective as $\mathrm{Al}_{2} \mathrm{O}_{3}$ to suppress the surface diffusion of Fe. This causes the Ostwald ripening and thus the bimodal distribution of CNT diameters [29].
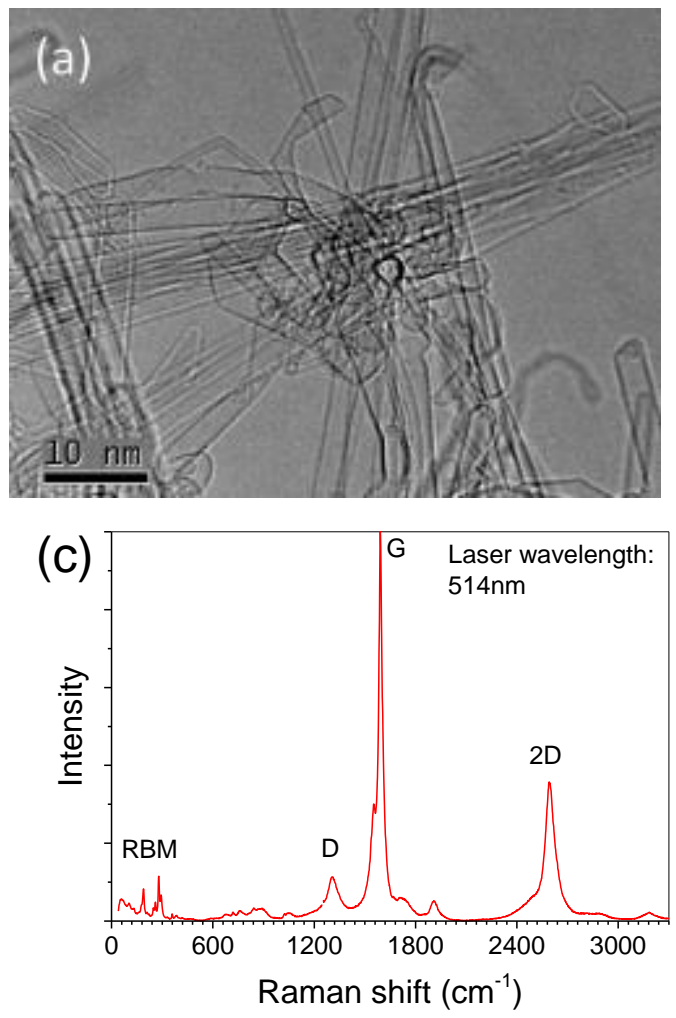
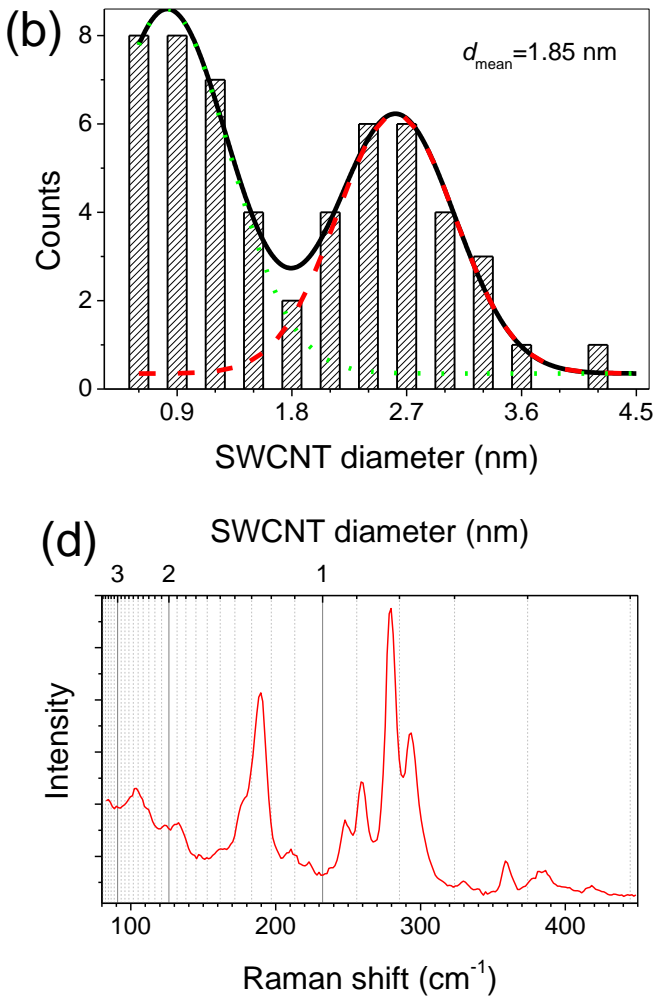

Fig. 2- TEM and Raman characterizations of SWCNT forests grown on $0.5 \mathrm{~nm} \mathrm{Al}$ (top) $/ 0.4 \mathrm{~nm} \mathrm{Fe} / 6 \mathrm{~nm} \mathrm{Al}$ /Cu foil. (a) A high resolution TEM image; (b) TEM histogram graph of SWCNT diameters, showing a very broad bimodal distribution; (c) A typical Raman spectrum of SWCNTs; (d) The detailed Raman spectrum of the SWCNT radial breathing mode in (c). The top X axis in (d) gives the corresponding diameter of SWCNTs, estimated from $d[\mathrm{~nm}]=212.36\left[\mathrm{~cm}^{-1} \cdot \mathrm{nm}\right] /(\omega-20.07)\left[\mathrm{cm}^{-1}\right]$ [28], where $d$ is the diameter of a SWCNT, $\omega$ is the frequency of the RBM peak.

Why can we grow high density SWCNT forests on $\mathrm{Cu}$ foils coated with Fe catalyst and $\mathrm{Al}$ layers as thin as 0.4 $\mathrm{nm}$ and $6 \mathrm{~nm}$, respectively? Previous studies show that it is essential to coat thicker than normal catalyst and $\mathrm{Al}_{2} \mathrm{O}_{3}$ barrier layers to grow MWCNT forests on $\mathrm{Cu}$. Lin et al. [24] reported that on unpolished $\mathrm{Cu}, 30 \mathrm{~nm}$ thick evaporated $\mathrm{Al}_{2} \mathrm{O}_{3}$ plus $3.5 \mathrm{~nm}$ Fe cannot enable the growth of CNT forests, however, $20 \mathrm{~nm} \mathrm{Al}_{2} \mathrm{O}_{3}$ prepared by atomic layer deposition (ALD) can lead to reproducible growth of MWCNT forests. The reason is that the evaporated $\mathrm{Al}_{2} \mathrm{O}_{3}$ is not only porous, but it also has a poor conformal coverage because of the point-source feature of evaporation. In contrast, ALD can produce conformal and dense but insulating $\mathrm{Al}_{2} \mathrm{O}_{3}$. The key in this study is to coat an $\mathrm{Al}$ film by DC magnetron sputtering with large area sputtering targets $(\Phi 100 \mathrm{~mm})$, which is believed to have a much better coating coverage than evaporation over steps and low aspect ratio features on the $\mathrm{Cu}$ foils [69]. It is also expected that the $\mathrm{Al}$ coating can be further densified because of volume expansion due to its oxidation into $\mathrm{AlO}_{\mathrm{x}}$ on exposure to air and during annealing.

In addition, we also followed the "Odako" method for the growth of CNT forests on CVD graphene/ Cu foils $[53,55]$. First, we sputter-coated sequentially $1 \mathrm{~nm} \mathrm{Fe}$ and $0-6 \mathrm{~nm} \mathrm{Al}$ on graphene/ Cu foils and $\mathrm{SiO}_{2}$ wafers. The latter were used as reference substrates. The $\mathrm{Al}$ should be oxidized into $\mathrm{AlO}_{x}$ too but as a capping layer rather than a barrier layer. Then, we performed the CNT growth experiments under the above mentioned conditions. Fig. S3 compares the CNT growth results. As can be seen, the $2 \mathrm{~nm} \mathrm{Al}$ is probably not able to form a 
continuous $\mathrm{AlO}_{\mathrm{x}}$ capping layer yet, so that CNTs can be grown on the smooth $\mathrm{SiO}_{2}$ substrates, but sparsely on the rough graphene/ $\mathrm{Cu}$ foils which is similar to the "Odako" growth. When the $\mathrm{Al}$ is over $4 \mathrm{~nm}$, we failed to grow CNT forests on both $\mathrm{SiO}_{2}$ and graphene/ $\mathrm{Cu}$ foils. This is in sharp contrast to Ref. [53] which showed successful growth of CNT forests with an $\mathrm{Al}_{2} \mathrm{O}_{3}$ capping layer up to $10 \mathrm{~nm}$ thick evaporated on graphene/ $\mathrm{Cu}$ foils. However, these experiments further confirm that our $\mathrm{AlO}_{\mathrm{x}}$ barrier layer is relatively dense and has a good coverage on $\mathrm{Cu}$ foils.

\subsection{TOF-SIMS and XPS analyses of the catalyst evolution}

To grow SWCNTs, annealing of the catalyst is essential. We investigated the effect of annealing on catalyst evolution with and without the $\mathrm{AlO}_{\mathrm{x}}$ barrier layer by means of TOF-SIMS. For this purpose, $\mathrm{Cu}$ foils were first patterned with a dot $(\sim \Phi 0.6 \mathrm{~mm})$ array of $20 \mathrm{~nm}$ thick Al using a shadow mask $(0.5 \mathrm{~mm}$ in thickness), then coated with $0.6 \mathrm{~nm} \mathrm{Fe}$ and $0.5 \mathrm{~nm} \mathrm{Al}$ all over the foils by removing the mask, as schematically illustrated in Fig. 3(a-c). Later, we performed simultaneous multiple element imaging by TOF-SIMS on such a sample before and after annealing in $\mathrm{H}_{2}$ at $740{ }^{\circ} \mathrm{C}, 15 \mathrm{mbar}$ for $6.5 \mathrm{~min}$ (including the ramping time). We also carried out depth profile analysis of two annealed samples by TOF-SIMS. Previously, SIMS elemental depth profiles were used to optimize the catalyst design [28, 42]. For comparison, Fig. 4 and Fig. 5 give the resulting multiple element images and depth profiles of $\mathrm{Fe}, \mathrm{Al}$ and $\mathrm{Cu}$, which are the focus of interest.
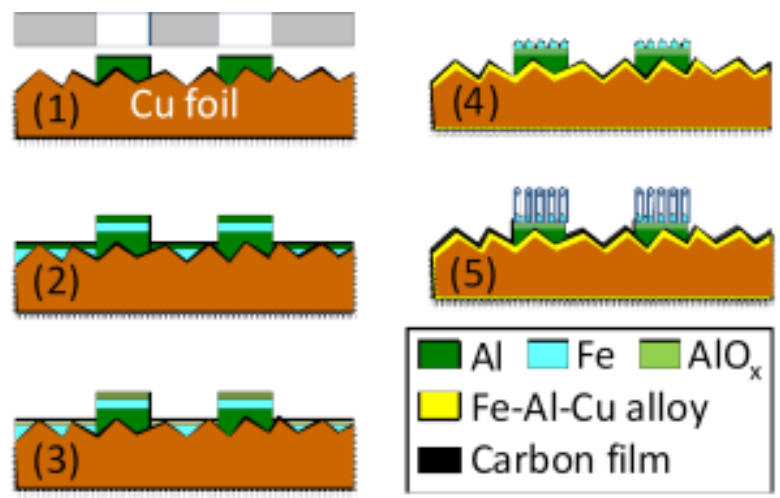

Fig.3- Schematic illustration of catalyst patterned on commercial $\mathrm{Cu}$ foils by magnetron sputtering and catalyst evolution during CVD process. (a) Patterning an Al layer on a Cu foil by a shadow mask. (b) Coating Fe (0.4$1.0 \mathrm{~nm})$ and $\mathrm{Al}(0.5 \mathrm{~nm})$ layers without the mask. (c) Formation of $\mathrm{Al}$ oxides on exposure of the substrate to air, the thick Al dot array oxidizes less completely than the surrounding ultrathin $0.5 \mathrm{~nm} \mathrm{Al}$. (d) Effect of annealing in $15 \mathrm{mbar}_{2}$ : 1) formation of catalyst nanoparticles on an $\mathrm{AlO}_{\mathrm{x}}$ barrier layer, 2) $\mathrm{Al}$ and $\mathrm{Fe}$ coatings diffuse into and alloy with $\mathrm{Cu}, 3$ ) further oxidization of $\mathrm{AlO}_{\mathrm{x}}$ by the surface oxides and residual $\mathrm{O}_{2} / \mathrm{H}_{2} \mathrm{O}$ in the CVD chamber. (e) Growth of CNT forests on the $\mathrm{AlO}_{\mathrm{x}}$ barrier layer and formation of a carbon film $\mathrm{Cu}$ where there is no any barrier layer.

In Fig. 4, it is notable that the color differences at regions $\mathrm{M}$ and $\mathrm{N}$, which represent the dot array of $0.5 \mathrm{~nm} \mathrm{Al}$ (top) $/ 0.6 \mathrm{~nm} \mathrm{Fe} / 20 \mathrm{~nm} \mathrm{Al} / \mathrm{Cu}$ foil and the area surrounding area of $0.5 \mathrm{~nm} \mathrm{Al}$ (top) $/ 0.6 \mathrm{~nm} \mathrm{Fe} / \mathrm{Cu}$ foil, respective, before and after annealing. Except for the $\mathrm{Al}^{+}$images (Fig. 4a, d), the color differences or changes in the $\mathrm{Fe}^{+}$and $\mathrm{Cu}^{+}$images are just as what as expected. We see that TOF-SIMS is a right choice for the study of catalyst evolution because it is very sensitive to the $\sim 1 \mathrm{~nm}$ topmost surface. Before annealing, Fe has a very uniform distribution all over the substrate (Fig. $4 \mathrm{~b}$ ), and $\mathrm{Cu}$ buried under $0.5 \mathrm{~nm} \mathrm{Al}+0.6 \mathrm{~nm}$ Fe can only be weakly detected (Fig. 4c).

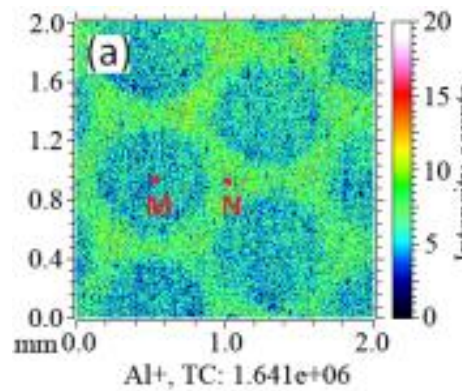

$\mathrm{Al}+\mathrm{TC}: 1.641 \mathrm{e}+06$

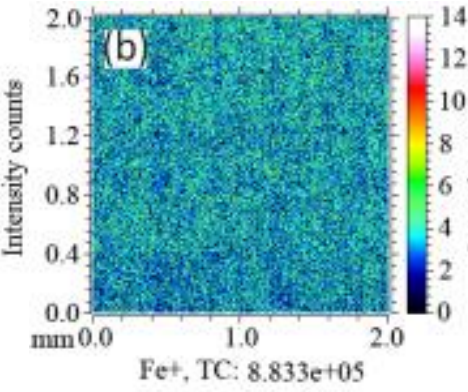

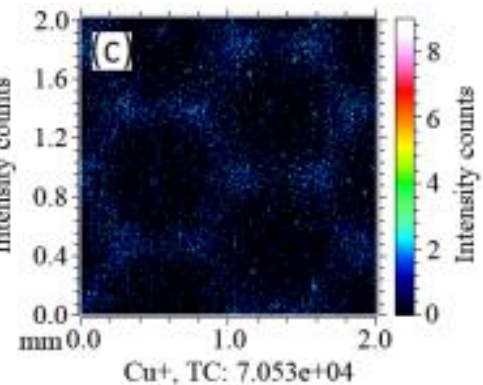




\section{Before annealing}
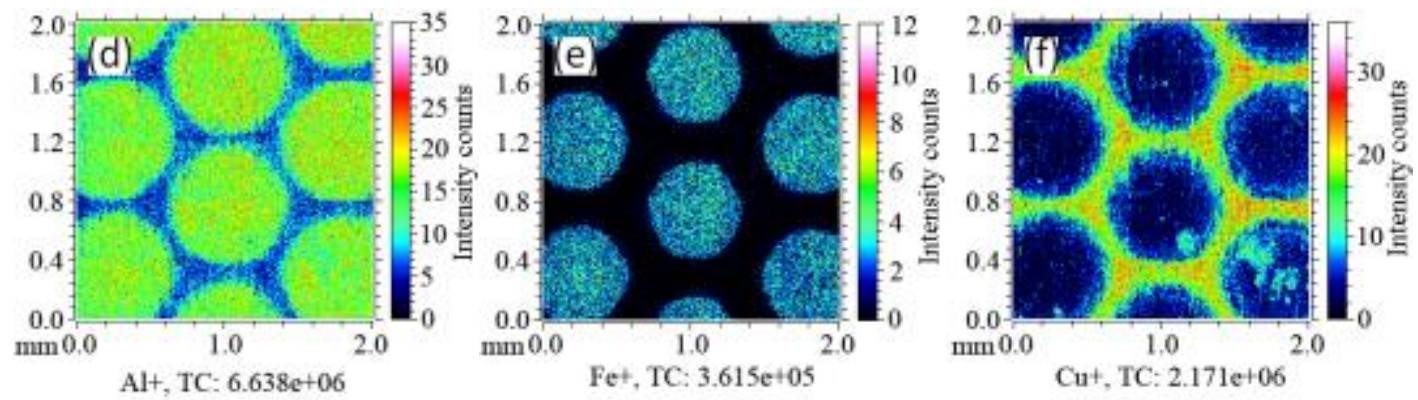

After annealing

Fig. 4- TOF-SIMS multi-element imaging from the surface of a $\mathrm{Cu}$ foil before and after annealing in $\mathrm{H}_{2}$ at $740{ }^{\circ} \mathrm{C}, 15$ mbar for $6.5 \mathrm{~min}$ (including the ramping time). The $\mathrm{Cu}$ foil was sputter-coated with first a dot ( $\sim \Phi 0.6$ $\mathrm{mm}$ ) array of $20 \mathrm{~nm}$ thick $\mathrm{Al}$ (nominal thickness) by using a shadow mask, then $0.6 \mathrm{~nm} \mathrm{Fe}$ and $0.5 \mathrm{~nm} \mathrm{Al}$ all over the foil by removing the mask. TC indicates the total counts of intensity.
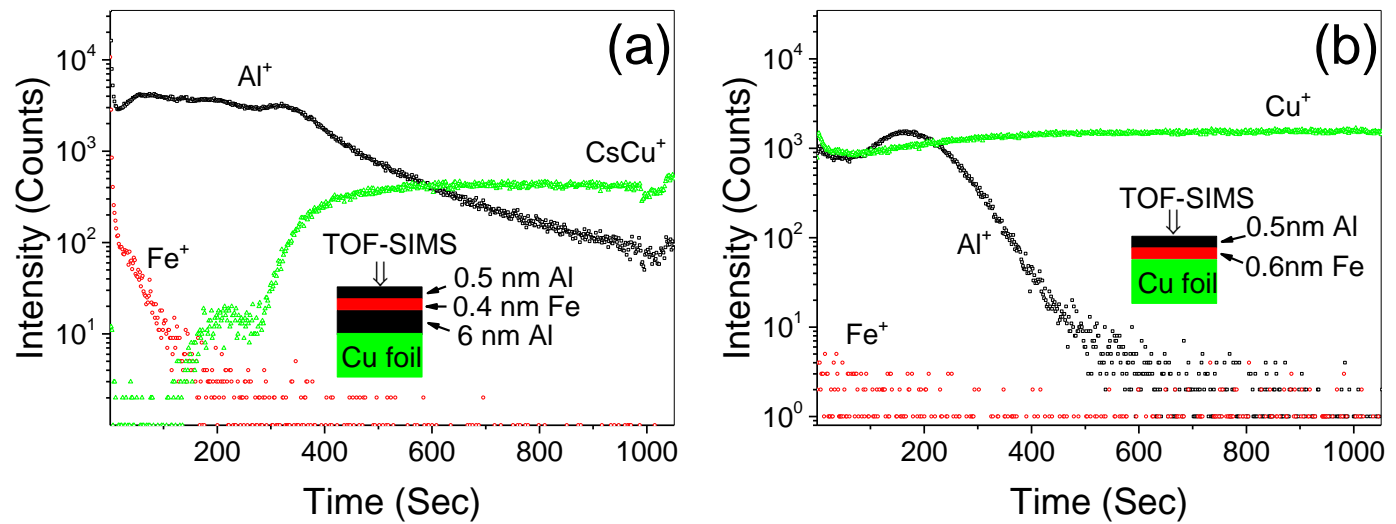

Fig. 5- TOF-SIMS depth profiles of $\mathrm{Fe}, \mathrm{Al}$ and $\mathrm{Cu}$ elements from two annealed $\mathrm{Cu}$ foils coated with (a) $0.5 \mathrm{~nm}$ $\mathrm{Al}$ (top) $/ 0.4 \mathrm{~nm} \mathrm{Fe} / 6 \mathrm{~nm} \mathrm{Al}$ and (b) $0.5 \mathrm{~nm} \mathrm{Al}$ (top) $/ 0.6 \mathrm{~nm}$ Fe, respectively. The annealing was carried out in pure $\mathrm{H}_{2}$ at $740{ }^{\circ} \mathrm{C}, 15 \mathrm{mbar}$ for $6.5 \mathrm{~min}$ (including the ramping time).

At region $\mathrm{N}$, as there is no barrier layer, the ultrathin $0.5 \mathrm{~nm} \mathrm{Al}$ especially the $0.6 \mathrm{~nm} \mathrm{Fe}$ catalyst diffused into the $\mathrm{Cu}$ base just after a short time annealing, leading to a $\mathrm{Cu}$-rich surface (Fig. 4d-f). Formation of solid solution with $\mathrm{Cu}$ means it is hard to form nanoparticles from $\mathrm{Fe}$ catalyst on $\mathrm{Cu}$ [49]. The higher $\mathrm{Al}^{+}$intensity at $\mathrm{N}$ than $\mathrm{M}$ is however unexpected in Fig. 4a because $\mathrm{Al}$ should be much richer at region $\mathrm{M}$. There are two possibilities to explain this phenomenon. 1) The chemical states of $\mathrm{Al}$ at regions $\mathrm{M}$ and $\mathrm{N}$ are different. 2) It contributes a lot to the intensity that an unknown element from the $\mathrm{Cu}$ base which has the same charge to mass ratio as $\mathrm{Al}^{+}$. If 2) is true, at region $\mathrm{N}$, it should have shown first a higher $\mathrm{Cu}^{+}$intensity before annealing (Fig. 4c), and second a higher $\mathrm{Al}^{+}$intensity after annealing (Fig. 4d) because the surface becomes $\mathrm{Cu}$ rich. However, the truth is that the $\mathrm{Al}^{+}$intensity becomes much weaker at region $\mathrm{N}$ and stronger at region $\mathrm{M}$ after annealing. Therefore, 1) is the only possibility to explain the intensity different in $\mathrm{Al}^{+}$images. It was reported that the secondary ion yield (in the form of intensity) is extremely sensitive to the surface chemistry (material structure and composition) [70]; the yield of $\mathrm{Al}$ is about 2 orders of magnitude lower from a clean surface than from an oxygen covered surface of an $\mathrm{Al}$ metal sputtered by $3 \mathrm{keV}$ argon ions. In our case, the surface $\mathrm{Al}$ was less oxidized at region $\mathrm{M}$ than region $\mathrm{N}$ on exposure to air because the barrier layer acts as a reservoir for oxygen. From the multiple element imaging, we can obtain more information about the catalyst evolution during the annealing:

- The higher $\mathrm{Al}^{+}$intensity at region $\mathrm{M}$ after annealing indicates that the $\mathrm{AlO}_{\mathrm{x}}$ barrier layer gets further oxidized by the surface oxides on the $\mathrm{Cu}$ foil and/or the residual $\mathrm{O}_{2} / \mathrm{H}_{2} \mathrm{O}$ in the CVD chamber during annealing despite of a reducing environment in $\mathrm{H}_{2}$ (see also Fig. 3d). This is similar to that of Ti and Ta barrier layers [34, 42].

- The $\mathrm{AlO}_{\mathrm{x}}$ barrier layer can efficiently prevent the loss of Fe catalyst during the annealing, so that the $\mathrm{Fe}$ catalyst at region $\mathrm{M}$ shows a very close intensity before and after annealing. This indicates that the $\mathrm{Fe}$ 
catalyst may be in the same chemical state before and after annealing (Fig. 4b, e) as both were exposed to air.

- The dot size imaged from Fe element is smaller than that from $\mathrm{Al}$ and $\mathrm{Cu}$ after annealing. As the dots were prepared by a thick shadow mask, the outer ring of each dot has a thickness gradient, varies from near zero to the nominal barrier layer thickness towards the center. Too thin a barrier layer at the outer ring could not efficiently prevent the Fe from losing during annealing, so that the dot size is reduced than that before annealing.

The effect of an $\mathrm{AlO}_{\mathrm{x}}$ barrier layer on catalyst evolution during annealing is also confirmed by SIMS depth profiles of $\mathrm{Fe}, \mathrm{Al}$ and $\mathrm{Cu}$ (Fig. 5) from two annealed $\mathrm{Cu}$ foils coated with $0.5 \mathrm{~nm} \mathrm{Al}$ (top) $/ 0.4 \mathrm{~nm} \mathrm{Fe} / 6 \mathrm{~nm} \mathrm{Al}$ and $0.5 \mathrm{~nm} \mathrm{Al}$ (top) $/ 0.6 \mathrm{~nm} \mathrm{Fe}$, respectively. After annealing, Fe on a $6 \mathrm{~nm}$ barrier layer shows at least 3 orders of magnitude higher surface intensity than that without the barrier layer; however, $\mathrm{Cu}$ shows reverse surface intensity.

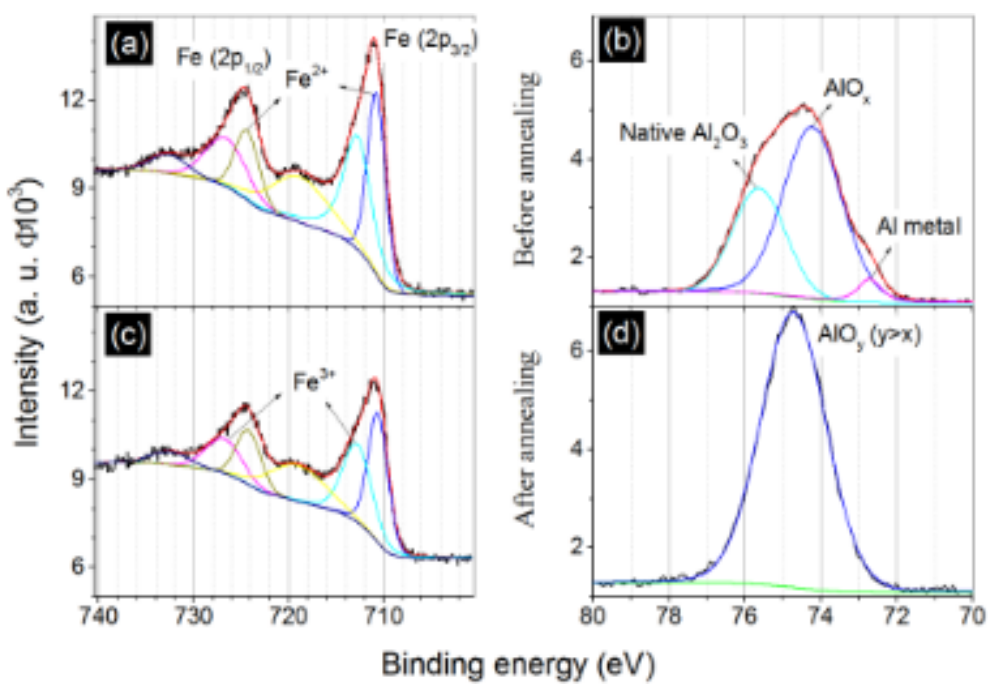

Fig. 6- High resolution XPS spectra of Fe $2 p(a, c)$ and $\mathrm{Al} 2 \mathrm{p} \mathrm{(b,d)} \mathrm{peaks} \mathrm{obtained} \mathrm{from} \mathrm{region} \mathrm{M} \mathrm{in} \mathrm{Fig.} 4$ of recently prepared samples, which are as the same as for TOF-SIMS element imaging, before (a, b) and after (c, d) annealing. Peak fitting was performed by a freeware of XPSpeak41, using a Shirley type background and a constrain relationship of area ratio of $2 p_{3 / 2}: 2 p_{1 / 2}=2: 1$. The sample had been exposed to air for about 1 month before the XPS measurement.

In order to investigate the chemical states of the catalyst and the barrier layer, XPS characterizations were performed on recently prepared samples, which are as the same as for SIMS element imaging. The results agree very well with the SIMS analysis. Fig. 6 shows the high resolution XPS spectra of the Fe $2 p$ and Al 2p peaks obtained from the top surface at region $\mathrm{M}$. Before annealing, it can be seen that the Fe catalyst exists in oxide forms of both $\mathrm{Fe}^{2+}$ and $\mathrm{Fe}^{3+}$ (Fig. 6a), while the $\mathrm{Al}$ exists in the forms of native oxide $\left(\mathrm{Al}_{2} \mathrm{O}_{3}\right), \mathrm{AlO}_{\mathrm{x}}$ and $\mathrm{Al}$ metal (Fig. 6b). As for the small metal component in the Al 2p peak, it should come from the subsurface as the XPS sampling depth is up to $10 \mathrm{~nm}$ [70]. It confirms that the thick barrier layer is not fully oxidized yet on exposure to air. After annealing, the Fe keeps almost the same chemical states as before annealing (Fig. 6c); but, it seems that the all the $\mathrm{Al}$ components have been changed into a uniform oxide form of $\mathrm{AlO}_{\mathrm{y}}$ (Fig. 6d). The slightly higher binding energy of $\mathrm{AlO}_{\mathrm{y}}$ indicates it is in a higher oxide state than the dominate $\mathrm{AlO}_{\mathrm{x}}$ component before annealing, i. e. $y>x$ (see also Fig. 3). 


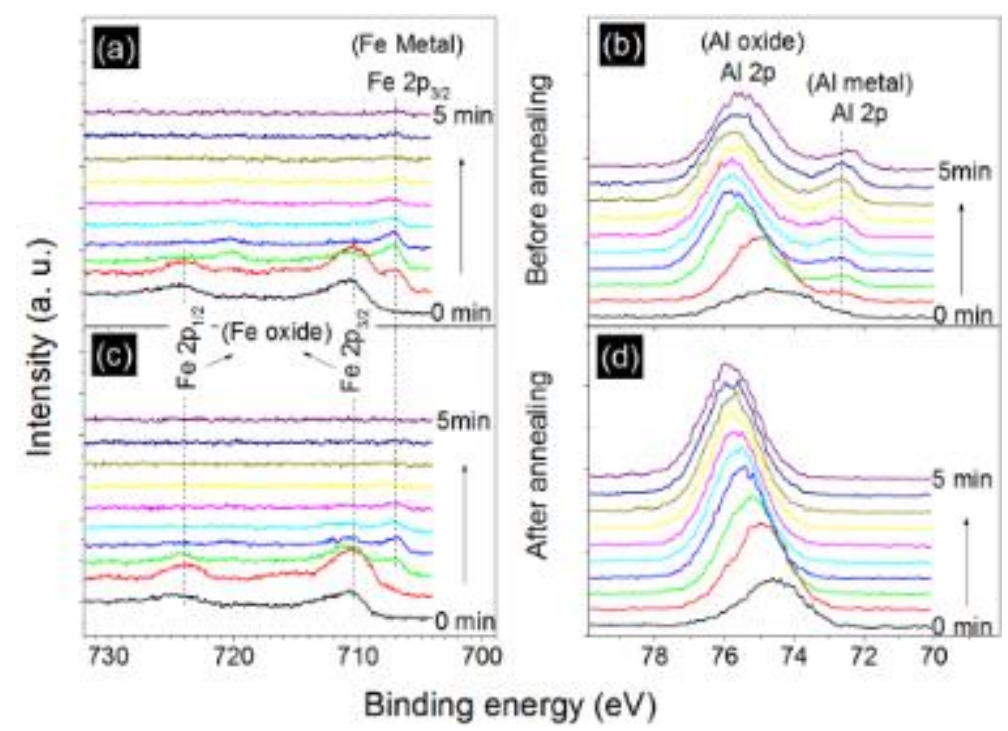

Fig. 7- Depth relationship of the chemical states of elements Al and Fe before (a, b) and after (c, d) annealing. The serial XPS spectra were collected from region M shown in Fig. 4a with a sputtering speed of $2.5 \mathrm{~nm} / \mathrm{min}$ calibrated from a standard $\mathrm{SiO}_{2}$ sample.

We also performed XPS analysis to disclose the chemical state changes with the coating depth. Fig. 7 plots a serial spectra of $\mathrm{Fe} 2 \mathrm{p}$ and $\mathrm{Al} 2 \mathrm{p}$ peaks collected simultaneously at region $\mathrm{M}$ in each cycle flushed by $1 \mathrm{kV} \mathrm{Ar}^{+}$ in an area of $2 \times 2 \mathrm{~mm}^{2}$ at a sputtering rate of $2.5 \mathrm{~nm} / \mathrm{min}$ calibrated from a standard $\mathrm{SiO}_{2}$ sample. As can be seen, the Fe catalyst changes from oxides into metal with the increase of depth despite of annealing or not, and its intensity decreases rapidly, which agrees with the SIMS depth profile of Fe. As for Al, the dominant component is no doubt $\mathrm{Al}$ oxide, however, a small but apparent $\mathrm{Al}$ metal 2p peak emerges with the increase of depth. After annealing only an $\mathrm{Al}$ oxide $2 \mathrm{p}$ peak can be detected even after $5 \mathrm{~min} \mathrm{Ar}^{+}$flushing. $\mathrm{The}^{+}$intensity keeps almost constant after the removal of the top most layer, this agrees with the fact that a thicker $\mathrm{AlO}_{\mathrm{x}}$ barrier layer was prepared. It also proves that exposure to air and annealing of our substrates can further oxidize and densify the barrier layer. It was reported that the oxide peak position may vary with the Al oxide thickness due to its insulating nature [71]. We did observe the $\mathrm{Al} 2 \mathrm{p}$ peak shift, however, it is not clear yet if there is any other reason such as a chemical state change. Because the XPS sampling depth is about one order of magnitude higher than our top most $\mathrm{Al} / \mathrm{Fe}$ coating, plus the $\mathrm{Al} 2 \mathrm{p}$ peak overlaps with the $\mathrm{Cu} 3 \mathrm{p}$ peak and $\mathrm{Al} 1 \mathrm{~S}$ peak with the $\mathrm{Cu}$ 3 s peak, respectively, we failed to obtain the chemical states of the surface $\mathrm{Al}$ at region $\mathrm{N}$.

After the TOF-SIMS analysis, CVD tests were carried out. We find that the CVD conditions must be optimized for $\mathrm{Cu}$ foils rather than just to follow our previous recipes for $\mathrm{Si}$ substrates $[28,59]$. The most important step is to suspend the foils by $\mathrm{Si}$ strip spacers to achieve uniform growth of CNT forests. The reason is that $\mathrm{Cu}$ foils can be easily deformed during the handling. Loading them directly onto a flat heater usually causes growth problems due to an uneven heating of the foils by point contacts rather than surface contact as for Si wafers. In order to decrease the catalyst loss by diffusion during annealing, it would be better to shorten the annealing time. By shortening the annealing time (including the ramping period) to within $1.5 \mathrm{~min}$, dense SWCNT forests can be reproducibly grown on $\mathrm{Cu}$ foils coated with $\mathrm{Fe}$ catalyst and $\mathrm{Al}$ as thin as $0.4 \mathrm{~nm}$ and $6 \mathrm{~nm}$, respectively. But the growth seems to be terminated within minutes. It is worth noting that annealing longer than 3 min will usually lead to growth failure of SWCNT forests. We attribute this to the continuous consuming of the barrier layer and catalyst through diffusion and alloying (Fig. 3d-e). If the thickness of the $\mathrm{Al}$ is less than $3 \mathrm{~nm}$, a carbon film is usually deposited with few disordered CNTs (Fig. 3e, Fig. S4), which agrees with reference [72]. The main reason is that a $3 \mathrm{~nm} \mathrm{Al}$ can hardly form a continuous film; and its alloying with $\mathrm{Cu}$ during annealing makes things worse. This further confirms that Fe nanoparticles can hardly be formed on Cu by dewetting without the aid of a proper barrier layer.

\subsection{Electrical properties of the SWCNT forests grown on $\mathrm{Cu}$ foils}

After the growth, our prime concern is the electrical contact between the SWCNT forests and the Cu foils. A two-point probe station was employed for the measurement by contacting one probe (tip diameter: $\sim 20 \mu \mathrm{m}$ ) with the forests and the other with the $\mathrm{Cu}$ foil where the as-grown CNTs were removed by tweezers. I-V curves were obtained from tens of CNT samples grown under various conditions. Most of the samples exhibit an Ohmic 
conductivity as illustrated in Fig. 8. Esconjauregui et al. [40] reported that an $\mathrm{Al}_{2} \mathrm{O}_{3}$ layer thicker than $4 \mathrm{~nm}$ would block the current flow at all, but Hiraoka et al. [50] demonstrated that CNT forests grown on $30 \mathrm{~nm}$ $\mathrm{Al}_{2} \mathrm{O}_{3} / \mathrm{Ni}$-based alloys were still conductive. In our case, the $\mathrm{AlO}_{\mathrm{x}}$ is much thinner, and it may be further thinned by diffusion and alloying. Therefore, a fraction of SWCNT forests might contact directly with the $\mathrm{Cu}$. The overall resistance derived from an I-V curve includes not only the resistances of the as-grown CNTs and the base $\mathrm{Cu}$ but also the contact resistances of probe to $\mathrm{CNT}, \mathrm{CNT}$ to $\mathrm{Cu}$, and probe to $\mathrm{Cu}$. Our best samples have overall resistances of $60-80 \mathrm{Ohms}$, which are the lowest measured by using the same method but from CNT forests grown on different conductive layers $[40,42,56,73]$. This implies that our results are very promising for applications of CNT forests grown on conductors.

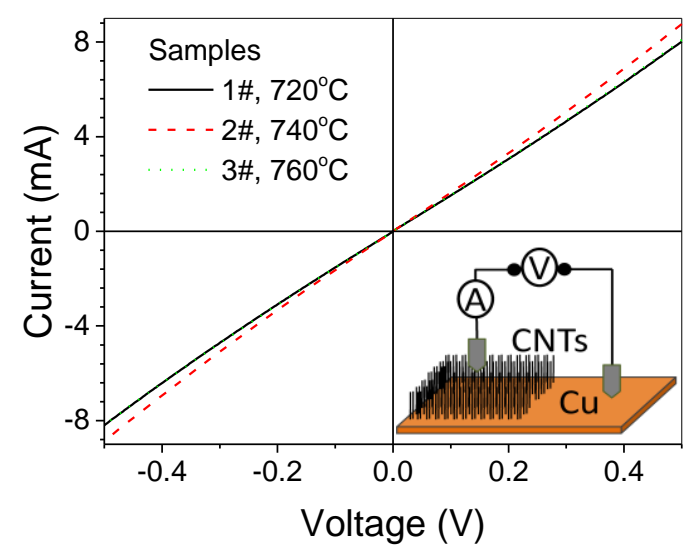

Fig. 8- Electrical properties of SWCNT forests grown on $\mathrm{Cu}$ foils measured by a two-point probe station; The inset illustrates that the measurement was carried out by contacting one probe with the top of CNTs and the other probe with the $\mathrm{Cu}$ substrate where the as-grown CNTs were removed by tweezers. The samples were prepared under the same conditions except for different growth temperatures.

\section{Conclusions}

High quality and high density SWCNT forests have been successfully and reproducibly prepared on Cu foils coated with $\mathrm{Fe}$ and $\mathrm{Al}$ as thin as $0.4 \mathrm{~nm}$ and $6 \mathrm{~nm}$, respectively. The as-grown SWCNTs exhibit a broad bimodal distribution of diameters, with two peaks centered at $0.8 \mathrm{~nm}$ and $2.6 \mathrm{~nm}$, respectively. Preparation of a proper $\mathrm{AlO}_{\mathrm{x}}$ barrier layer is of very importance for the growth of SWCNT forests on rough Cu foils. TOF-SIMS analysis by simultaneous multiple element imaging and depth profile indicates that Fe catalyst coated directly on $\mathrm{Cu}$ can rapidly diffuse into the $\mathrm{Cu}$ base in a short-time annealing. XPS analysis discloses that most of the sputtering coated $\mathrm{Al}$ has already oxidized into $\mathrm{AlO}_{\mathrm{x}}$ on exposure to air, and all should be changed into a uniform oxide by annealing even in a reducing environment. $\mathrm{Fe}^{2+}$ and $\mathrm{Fe}^{3+}$ oxides coexist on the surface, and $\mathrm{Fe}$ metal can exist beneath the surface despite of annealing or not. Electrical property measurement by a two-point probe station demonstrates that most of the as-grown SWCNT forests have an Ohmic contact with the Cu base, and an overall resistance as low as several tens Ohms can be achieved. These results make our SWCNT forests grown on commercial $\mathrm{Cu}$ foils very promising for applications such as supper-capacitors, batteries and thermal interfaces.

\section{Acknowledgement}

This work supported by Honda Research Institute USA Inc. Sugime H. acknowledges a research fellowship from the Japanese Society for the Promotion of Science (JSPS).

\section{References}

[1] Niu CM, Sichel EK, Hoch R, Moy D, Tennent H. High power electrochemical capacitors based on carbon nanotube electrodes. Appl Phys Lett. 1997;70:1480-2.

[2] Futaba DN, Hata K, Yamada T, Hiraoka T, Hayamizu Y, Kakudate Y, et al. Shape-engineerable and highly densely packed single-walled carbon nanotubes and their application as super-capacitor electrodes. Nat Mater. 2006;5:987-94.

[3] Simon P, Gogotsi Y. Materials for electrochemical capacitors. Nat Mater. 2008;7:845-54. 
[4] Dalton AB, Collins S, Munoz E, Razal JM, Ebron VH, Ferraris JP, et al. Super-tough carbon-nanotube fibres - these extraordinary composite fibres can be woven into electronic textiles. Nature. 2003;423:703.

[5] $\mathrm{Hu}$ L, Hecht DS, Gruner G. Percolation in transparent and conducting carbon nanotube networks. Nano Lett. 2004;4:2513-7.

[6] Hellstrom SL, Lee HW, Bao ZN. Polymer-assisted direct deposition of uniform carbon nanotube bundle networks for high performance transparent electrodes. ACS Nano. 2009;3:1423-30.

[7] Hecht DS, Hu LB, Irvin G. Emerging transparent electrodes based on thin films of carbon nanotubes, graphene, and metallic nanostructures. Adv Mater. 2011;23:1482-513.

[8] Lau KKS, Bico J, Teo KBK, Chhowalla M, Amaratunga GAJ, Milne WI, et al. Superhydrophobic carbon nanotube forests. Nano Lett. 2003;3:1701-5.

[9] Ge L, Sethi S, Ci L, Ajayan PM, Dhinojwala A. Carbon nanotube-based synthetic gecko tapes. Proc Natl Acad Sci USA. 2007;104:10792-5.

[10] Qu LT, Dai LM, Stone M, Xia ZH, Wang ZL. Carbon nanotube arrays with strong shear binding-on and easy normal lifting-off. Science. 2008;322:238-42.

[11] Chen BA, Oppenheimer PG, Shean TAV, Wirth CT, Hofmann S, Robertson J. Adhesive properties of gecko-inspired mimetic via micropatterned carbon nanotube forests. J Phys Chem C. 2012;116:20047-53.

[12] Hayamizu Y, Yamada T, Mizuno K, Davis RC, Futaba DN, Yumura M, et al. Integrated threedimensional microelectromechanical devices from processable carbon nanotube wafers. Nat Nanotechnol. 2008;3:289-94.

[13] Acquaviva D, Arun A, Esconjauregui S, Bouvet D, Robertson J, Smajda R, et al. Capacitive nanoelectromechanical switch based on suspended carbon nanotube array. Appl Phys Lett. 2010;97:233508.

[14] Fan SS, Chapline MG, Franklin NR, Tombler TW, Cassell AM, Dai HJ. Self-oriented regular arrays of carbon nanotubes and their field emission properties. Science. 1999;283:512-4.

[15] Milne WI, Teo KBK, Amaratunga GAJ, Legagneux P, Gangloff L, Schnell JP, et al. Carbon nanotubes as field emission sources. J Mater Chem. 2004;14:933-43.

[16] Robertson J, Zhong G, Telg H, Thomsen C, Warner JH, Briggs GAD, et al. Growth and characterization of high-density mats of single-walled carbon nanotubes for interconnects. Appl Phys Lett. 2008;93:163111.

[17] Awano Y, Sato S, Nihei M, Sakai T, Ohno Y, Mizutani T. Carbon nanotubes for VLSI: Interconnect and transistor applications. Proc IEEE. 2010;98:2015-31.

[18] Dijon J, Okuno H, Fayolle M, Vo T, Pontcharra J, Acquaviva D, et al. Ultra-high density carbon nanotubes on Al-Cu for advanced vias. 2010 International Electron Devices Meeting - Technical Digest. 2010:p. 33.4.1-4.4.

[19] Esconjauregui S, Fouquet M, Bayer BC, Ducati C, Smajda R, Hofmann S, et al. Growth of ultrahigh density vertically aligned carbon nanotube forests for interconnects. ACS Nano. 2010;4:7431-6.

[20] Robertson J, Zhong GF, Esconjauregui CS, Bayer BC, Zhang C, Fouquet M, et al. Applications of carbon nanotubes grown by chemical vapor deposition. Jpn J Appl Phys. 2012;51:01AH.

[21] Chen GG, Paronyan TM, Pigos EM, Harutyunyan AR. Enhanced gas sensing in pristine carbon nanotubes under continuous ultraviolet light illumination. Sci Rep. 2012;2:343.

[22] Biercuk MJ, Llaguno MC, Radosavljevic M, Hyun JK, Johnson AT, Fischer JE. Carbon nanotube composites for thermal management. Appl Phys Lett. 2002;80:2767-9.

[23] Huang H, Liu CH, Wu Y, Fan SS. Aligned carbon nanotube composite films for thermal management. Adv Mater. 2005; 17:1652-6.

[24] Lin W, Zhang RW, Moon KS, Wong CP. Synthesis of high-quality vertically aligned carbon nanotubes on bulk copper substrate for thermal management. IEEE Trans Adv Packag. 2010;33:370-6.

[25] Hata K, Futaba DN, Mizuno K, Namai T, Yumura M, Iijima S. Water-assisted highly efficient synthesis of impurity-free single-waited carbon nanotubes. Science. 2004;306:1362-4.

[26] Zhong GF, Iwasaki T, Kawarada H. Semi-quantitative study on the fabrication of densely packed and vertically aligned single-walled carbon nanotubes. Carbon. 2006;44:2009-14.

[27] Noda S, Hasegawa K, Sugime H, Kakehi K, Zhang ZY, Maruyama S, et al. Millimeter-thick singlewalled carbon nanotube forests: Hidden role of catalyst support. Jpn J Appl Phys, Part 2. 2007;46:L399-L401.

[28] Zhong GF, Warner JH, Fouquet M, Robertson AW, Chen BA, Robertson J. Growth of ultrahigh density single-walled carbon nanotube forests by improved catalyst design. ACS Nano. 2012;6:2893-903. 
[29] Mattevi C, Wirth CT, Hofmann S, Blume R, Cantoro M, Ducati C, et al. In-situ X-ray photoelectron spectroscopy study of catalyst-support interactions and growth of carbon nanotube forests. J Phys Chem C. 2008;112:12207-13.

[30] Kim SM, Pint CL, Amama PB, Zakharov DN, Hauge RH, Maruyama B, et al. Evolution in catalyst morphology leads to carbon nanotube growth termination. J Phys Chem Lett. 2010;1:918-22.

[31] Sakurai S, Nishino H, Futaba DN, Yasuda S, Yamada T, Maigne A, et al. Role of subsurface diffusion and ostwald ripening in catalyst formation for single-walled carbon nanotube forest growth. JACS. 2012; 134:2148-53.

[32] Zhang C, Yan F, Allen CS, Bayer BC, Hofmann S, Hickey BJ, et al. Growth of vertically-aligned carbon nanotube forests on conductive cobalt disilicide support. J Appl Phys. 2010;108:024311.

[33] Nessim GD, Acquaviva D, Seita M, O'Brien KP, Thompson CV. The critical role of the underlayer material and thickness in growing vertically aligned carbon nanotubes and nanofibers on metallic substrates by chemical vapor deposition. Adv Funct Mater. 2010;20:1306-12.

[34] Bayer BC, Hofmann S, Castellarin-Cudia C, Blume R, Baehtz C, Esconjauregui S, et al. Supportcatalyst-gas interactions during carbon nanotube growth on metallic Ta films. J Phys Chem C. 2011;115:435969.

[35] Bayer BC, Zhang C, Blume R, Yan F, Fouquet M, Wirth CT, et al. In-situ study of growth of carbon nanotube forests on conductive CoSi2 support. J Appl Phys. 2011;109:114314.

[36] Bayer BC, Fouquet M, Blume R, Wirth CT, Weatherup RS, Ogata K, et al. Co-catalytic solid-state reduction applied to carbon nanotube growth. J Phys Chem C. 2012;116:1107-13.

[37] Horibe M, Nihei M, Kondo D, Kawabata A, Awano Y. Carbon nanotube growth technologies using tantalum barrier layer for future ulsis with $\mathrm{Cu} / \mathrm{low}-\mathrm{k}$ interconnect processes. Jpn J Appl Phys, Part 1. 2005;44:5309-12.

[38] Esconjauregui S, Bayer BC, Fouquet M, Wirth CT, Ducati C, Hofmann S, et al. Growth of high-density vertically aligned arrays of carbon nanotubes by plasma-assisted catalyst pretreatment. Appl Phys Lett. 2009;95.

[39] Yamazaki Y, Katagiri M, Sakuma N, Suzuki M, Sato S, Nihei M, et al. Synthesis of a closely packed carbon nanotube forest by a multi-step growth method using plasma-based chemical vapor deposition. Appl Phys Express. 2010;3:055002.

[40] Esconjauregui S, Xie RS, Guo YZ, Pfaendler SML, Fouquet M, Gillen R, et al. Electrical conduction of carbon nanotube forests through sub-nanometric films of alumina. Appl Phys Lett. 2013;102:113109.

[41] Sugime H, Esconjauregui S, Yang JW, D'Arsie L, Oliver RA, Bhardwaj S, et al. Low temperature growth of ultra-high mass density carbon nanotube forests on conductive supports. Appl Phys Lett. 2013;103:073116.

[42] Zhong GF, Xie R, Yang J, Robertson J. Single-step CVD growth of high-density carbon nanotube forests on metallic Ti coatings through catalyst engineering. Carbon. 2014;67:680-7.

[43] Yang J, Esconjauregui S, Robertson AW, Guo Y, Hallam T, Sugime H, et al. Growth of high-density carbon nanotube forests on conductive TiSiN supports. Appl Phys Lett. 2015;106:083108.

[44] Wang BA, Liu XY, Liu HM, Wu DX, Wang HP, Jiang JM, et al. Controllable preparation of patterns of aligned carbon nanotubes on metals and metal-coated silicon substrates. J Mater Chem. 2003;13:1124-6.

[45] Parthangal PM, Cavicchi RE, Zachariah MR. A generic process of growing aligned carbon nanotube arrays on metals and metal alloys. Nanotechnology. 2007;18:185605.

[46] Kim SM, Gangloff L. Thermal chemical vapor deposition (t-CVD) growth of carbon nanotubes on different metallic underlayers. Physica E. 2011;43:1481-5.

[47] Atthipalli G, Epur R, Kumta PN, Yang MJ, Lee JK, Gray JL. Nickel catalyst-assisted vertical growth of dense carbon nanotube forests on bulk copper. J Phys Chem C. 2011;115:3534-8.

[48] Atthipalli G, Tang Y, Star A, Gray JL. Electrochemical characterization of carbon nanotube forests grown on copper foil using transition metal catalysts. Thin Solid Films. 2011;520:1651-5.

[49] Delage S, Legrand B, Soisson F, Saul A. Dissolution modes of Fe/Cu and Cu/Fe deposits. Phys Rev B. 1998;58:15810-20.

[50] Hiraoka T, Yamada T, Hata K, Futaba DN, Kurachi H, Uemura S, et al. Synthesis of single- and double-walled carbon nanotube forests on conducting metal foils. JACS. 2006;128:13338-9.

[51] Li G, Chakrabarti S, Schulz M, Shanov V. Growth of aligned multiwalled carbon nanotubes on bulk copper substrates by chemical vapor deposition. J Mater Res. 2009;24:2813-20.

[52] Lee BJ, Kim JJ, Choi KH, Shin EC, Kim WJ, Lee SM, et al. Direct growth of vertically aligned carbon nanotubes on $\mathrm{Cu}$ foils for applications in lithium ion batteries. Surf Rev Lett. 2010;17:87-91. 
[53] Zhu Y, Li L, Zhang CG, Casillas G, Sun ZZ, Yan Z, et al. A seamless three-dimensional carbon nanotube graphene hybrid material. Nat Commun. 2012;3:1225.

[54] Rao RH, Chen GG, Arava LMR, Kalaga K, Ishigami M, Heinz TF, et al. Graphene as an atomically thin interface for growth of vertically aligned carbon nanotubes. Sci Rep. 2013;3:1891.

[55] Pint CL, Alvarez NT, Hauge RH. Odako growth of dense arrays of single-walled carbon nanotubes attached to carbon surfaces. Nano Res. 2009;2:526-34.

[56] Talapatra S, Kar S, Pal SK, Vajtai R, Ci L, Victor P, et al. Direct growth of aligned carbon nanotubes on bulk metals. Nat Nanotechnol. 2006;1:112-6.

[57] Wang H, Feng JY, Hu XJ, Ng KM. Synthesis of aligned carbon nanotubes on double-sided metallic substrate by chemical vapor deposition. J Phys Chem C. 2007;111:12617-24.

[58] Atthipalli G, Wang H, Gray JL. Catalyst-assisted vertical growth of carbon nanotubes on inconel coated commercial copper foil substrates versus sputtered copper films. Appl Surf Sci. 2013;273:515-9.

[59] Zhong G, Hofmann S, Yan F, Telg H, Warner JH, Eder D, et al. Acetylene: A key growth precursor for single-walled carbon nanotube forests. J Phys Chem C. 2009;113:17321-5.

[60] Zhong GF, Iwasaki T, Honda K, Furukawa Y, Ohdomari I, Kawarada H. Very high yield growth of vertically aligned single-walled carbon nanotubes by point-arc microwave plasma CVD. Chem Vap Deposition. 2005;11:127-30.

[61] Xu M, Futaba DN, Yumura M, Hata K. Alignment control of carbon nanotube forest from random to nearly perfectly aligned by utilizing the crowding effect. ACS Nano. 2012;6:5837-44.

[62] Liu K, Jiang KL, Feng C, Chen Z, Fan SS. A growth mark method for studying growth mechanism of carbon nanotube arrays. Carbon. 2005;43:2850-6.

[63] Iwasaki T, Zhong GF, Aikawa T, Yoshida T, Kawarada H. Direct evidence for root growth of vertically aligned single-walled carbon nanotubes by microwave plasma chemical vapor deposition. J Phys Chem B. 2005;109:19556-9.

[64] DiLeo RA, Landi BJ, Raffaelle RP. Purity assessment of multiwalled carbon nanotubes by raman spectroscopy. J Appl Phys. 2007;101:064307.

[65] Sugime H, Noda S, Maruyama S, Yamaguchi Y. Multiple "optimum" conditions for Co-Mo catalyzed growth of vertically aligned single-walled carbon nanotube forests. Carbon. 2009;47:234-41.

[66] Amama PB, Pint CL, McJilton L, Kim SM, Stach EA, Murray PT, et al. Role of water in super growth of single-walled carbon nanotube carpets. Nano Lett. 2009;9:44-9.

[67] Hasegawa K, Noda S. Moderating carbon supply and suppressing ostwald ripening of catalyst particles to produce 4.5-mm-tall single-walled carbon nanotube forests. Carbon. 2011;49:4497-504.

[68] Youn SK, Frouzakis CE, Gopi BP, Robertson J, Teo KBK, Park HG. Temperature gradient chemical vapor deposition of vertically aligned carbon nanotubes. Carbon. 2013;54:343-52.

[69] Sarkar J. Sputtering materials for VLSI and thin film devices. Waltham Mass.: William Andrew; 2014.

[70] Van der Heide P. X-ray photoelectron spectroscopy : An introduction to principles and practices. Hoboken, N.J.: Wiley; 2012.

[71] Xpssimplified.Com [internet]. Thermo fisher scientific inc. Xps knowledge base organized according to the periodic table of elements. [cited 2015 Nov 10]; Available from: http://xpssimplified.com/elements/aluminum.php.

[72] Zhu JT, Jia JC, Kwong FL, Ng DHL. Synthesis of bamboo-like carbon nanotubes on a copper foil by catalytic chemical vapor deposition from ethanol. Carbon. 2012;50:2504-12.

[73] Esconjauregui S, Bayer BC, Fouquet M, Wirth CT, Yan F, Xie R, et al. Use of plasma treatment to grow carbon nanotube forests on TiN substrate. J Appl Phys. 2011;109:114312. 